\title{
ЛИЧНОСТНЫЕ КАЧЕСТВА СТАРШЕКЛАССНИКОВ С КРИТИЧЕСКИМ МЫШЛЕНИЕМ
}

Белоусова А.К. (Донской государственный технический университет,

\author{
Ростов-на-Дону, Россия) \\ belousovaak@gmail.com

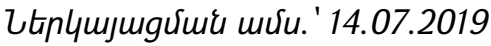

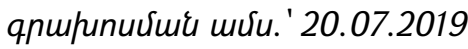

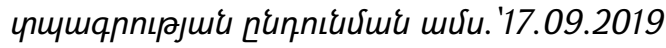

В статье дается обзор современных представлений о критическом мышлении. На основе анализа исследований автор раскрывает особенности критического мышления, характерные старшеклассникам, выделяет психологические детерминанты развития критического мышления. Автор формулирует собственную позицию, в основе которой лежит представление о доминировании функции селекции в процессах мышления людей с доминирующим критическим мышлением. Функция селекции, по мысли автора, заключается в оценке, отборе, отсеве и проверке информации, поступающей к человеку. Автор формулирует гипотезу исследования, в соответствии с которой старшеклассники имеют определенный набор психологических факторов и особенностей мотивации достижения успеха, которые связаны с критическими мышлением. Представлены результаты эмпирического исследования критического мышления старшеклассников, которых демонстрируют взаимосвязь фракторов Е, М, Н, Q4 с критичностью мышления.

Ключевые слова: Критическое мышление, психологические детерминанты, рефрлексивность, юношеский возраст, оценочная деятельность, самостоятельность мышления

В последнее время в связи с реформированием российского общества происходят глубокие трансформации, связанные с нестабильностью, неопределенностью, неустойчивостью социальных, политических, экономических процессов, которые порождают у человека кризисные психологические состояния, как эмоционального, интеллектуального, так и личностного характера. Кризисные психологические состояния могут приводить к сомнениям, потере традиционных ценностей, слому установок, возникновению деструктивных и неадаптивных паттернов поведения. Особенно это касается молодёжи, восприимчивой к вызовам современности и тем противоречиям, которые она обнаруживает в социальной сфере. Молодёжь выступает такой социальной группой, для которой характерными являются: легкость восприятия, принятия и усвоения новых идей; эмоциональная восприимчивость, тревожность; поиск личностного и жизненного выбора, стремление 
переосмыслить нравственные и ценностные истины, - которые сочетаются с категоричностью, прямолинейностью, императивностью принятых решений [9].

Своеобразие психологических особенностей личности юношеского возраста в сумме с неустойчивостью сформированных ценностно-смысловых структур сознания выступают той психологической основой, сквозь фрильтр которой проходит новая информация, воспринимаются ценности, формируются интересы и мотивы, происходит адаптация к социокультурным условиям. Одним из путей, который позволит формировать и развивать конструктивные поведенческие стратегии поведения, адаптивность, активную жизненную позицию, выступает развитие суверенизации личности, её самостоятельности. Мышление человека является одним из способов развития суверенности личности, но также и её проявлением. Способность воспринимать, осмысливать получаемую информацию, размышлять о ней, анализировать, отделять существенное и несущественное, выделять достоверную и недостоверную информацию, критически перерабатывать полученную информацию - это всё операции, которые относятся к мышлению и мыслительной деятельности человека.

Несомненную актуальность имеют выстроенные на основе современных психологических концепций исследования личностных ресурсов старшеклассников, обеспечивающих психологическую устойчивость к манипулятивным и деструктивным воздействиям. Анализ существующих исследований показывает, что существуют психолого-педагогические условия, которые обеспечивают успешное развитие личностных ресурсов, определяющих устойчивость старшеклассников к деструктивному влиянию: организация психологического сопровождения педагогического процесса, основанного на принципах ресурсного подхода; ориентация психолого-педагогического воздействия на осознание старшеклассниками механизмов и способов манипулятивного воздействия и на формирование личностных качеств, обеспечивающих психологическую устойчивость человека, на рефлексию старшеклассниками своих личностных ресурсов как фактора устойчивости к деструктивному влиянию, на развитие критического мышления как когнитивного ресурса личности.

Можно сказать, что в настоящее время одной из важнейших задач является формирование мыслящего человека, имеющего собственную жизненную позицию, способного к постановке и развитию жизненных целей, аргументации своей позиции и владеющего навыками доказательства своей правоты. В соответствии с существующими в литературе представлениями этим требованиям отвечает критическое мышление, которое предполагает умение видеть проблемы, готовность к решению задач, рефлексию своей интеллектуальной деятельности [2], [3], [4], [5], [6], [7], [8].

В современной литературе существует множество определений критического мышления. Е.В.Волков считает, что критическое мышление характеризуется 
«обоснованностью и целенаправленностью, - такой тип мышления, к которому прибегают при решении задач, формулирования выводов, вероятностной оценке и принятии решений» [3, с.5].

Е.О.Галицких полагает, что критическое мышление «повышает уровень культуры индивидуальной работы с информацией, фрормирует умение анализировать и делать самостоятельные выводы, прогнозировать последствия своих решений и отвечать за них» [4, с.112].

В.Н. Брюшинкин пишет, что «критическое мышление - последовательность умственных действий, направленных на проверку высказываний или систем высказываний с целью выяснения их несоответствия принимаемым фактам, нормам или ценностям. ... Существуют уровни критического мышления, для каждого из которых есть свой вид аргументации, характеризующийся различными соотношениями логической и когнитивной компоненты: 1)эмпирический уровень критическая проверка фактов; 2) теоретический уровень - критическая проверка теорий; 3) метатеоретический уровень - критическая проверка норм и ценностей» [2, с 30].

Г.В.Сорина считает, что критическое мышление предполагает наличие навыков рефлексии относительно собственной мыслительной деятельности, умение работать с понятиями, суждениями, умозаключениями, вопросами, развитие способностей к аналитической деятельности, а также к оценке аналогичных возможностей других людей [6].

По мнению Е.И.Федотовской, механизм критического мышления включает мыслительные операции, определяющие процесс рассуждения и аргументации: постановку цели, выявление проблемы, выдвижение гипотез, приведение аргументов, их обоснование, прогнозирование последствий, принятие или непринятие альтернативных точек зрения [7].

Таким образом, в современных условиях понятие «критическое мышление» трансформируется, наполняется новым содержанием, рассматривается как свойство критической личности.

В соответствии с нашими представлениями в случае критического мышления на первый план выходит оценочная деятельность человека, опережающая продуктивные, порождающие эффректы. Самым существенным и показательным у людей с таким мышлением является стремление оценивать планы, гипотезы, цели, знания, в целом - личность и деятельность другого человека (или других людей). Критическое мышление направлено на оценку, тестирование получаемой информации. Оно выражается, прежде всего, в способности человека видеть слабые места, ошибки, разного рода недочеты. Причем сама оценочная деятельность, возможность критики, оценки, анализа (как в теоретическом, так и в практическом плане), мотивируют действия человека, создают положительные эмоции: человеку нравится этим заниматься. Его скепсис, рассудительность, 
критичность подчеркивают окружающие. «Критик» легко вырабатывает новые оценки, замечания, аргументы, хотя последние способствуют скорее динамике деятельности, а не ее продуктивности. Мышление «критика» легко вырабатывает новые оценки, аргументы, гипотезы. Этим критик отличается от генератора, который вырабатывает новые предложения и идеи. Самым существенным и показательным для такого мышления является стремление оценивать планы, гипотезы, цели, знания, в целом - личность и деятельность другого человека. Критическое мышление присуще субъектам, которые селективны, аналитичны, умеют выделить главное и найти недостатки в рассматриваемом вопросе [1].

Несомненный интерес представляет работа Д. Халперн, которая внесла значительный вклад в изучение критического мышления. Д. Халперн считает, что критическое мышление - это использование когнитивных техник или стратегий, которые увеличивают вероятность получения желаемого конечного результата. С точки зрения Д. Халперн, критическое мышление предполагает оценочный компонент, который проявляется в трансляции и позитивного, и негативного отношения к предметам, явлениям окружающего мира. Д. Халперн определяет следующие качества человека с критическим мышлением: готовность к планированию, гибкость, настойчивость, готовность исправлять свои ошибки, осознание и анализ собственных рассуждений, поиск компромиссных решений [9].

Р. Пол, рассматривая особенности критического мышления, выделяет следующие черты, которые необходимо формировать у студентов для развития критического мышления: интеллектуальное смирение - осознание ограниченности знаний; интеллектуальная смелость способность оценивать идеи, независимо отношения к ним; интеллектуальное сочувствие - способность стать на интеллектуальную позицию другого человека; интеллектуальные честные намерения четность по отношению к своим интеллектуальным построениям; интеллектуальная настойчивость - достижение цели понимания интеллектуальной задачи или проблемы; вера в причину - готовность выстраивать свои рассуждения и уверенность в правильности своих действий. Интеллектуальное смысловое правосудие предполагает толерантность к позициям и точкам зрения других людей, готовность ассимилировать их и оценивать в соответствии с одинаковыми критериями, сформированными для всех остальных задач и проблем [10].

Из этого следует, что человек, обладающий способностью к критическому мышлению должен отличаться соответствующим уровнем интеллектуальных способностей [7].

Становление мышления происходит непрерывно в процессе развития человека. Однако существуют некоторые возрастные особенности в выраженности и доминировании каждого вида. Так пик выраженности критического стиля приходится на старший школьный возраст (15-17 лет). Мы полагаем, что это связано с протекающим в этот период становлением личности, фрормированием 
мировоззрения и «Я - концепции» в целом, становлением ценностно-смысловых структур сознания, собственных установок, мнений [1].

С целью изучения развития критического мышления в юношеском возрасте под нашим руководством было проведены исследование, в котором приняли участие 120 старшеклассников средних школ г. Ростова-на-Дону. Для определения выраженности критического мышления была использована методика А.К.Белоусовой [1], с целью выявления личностных качеств школьников с критическим мышлением использовался опросник Р.Б. Кеттелла, методика диагностики личности на мотивацию к достижению успеха Т. Элерса.

Анализ полученных результатов позволяет говорить, что следующие факторы по методике Кеттелла коррелируют с показателем критичности мышления: фактор E - «подчиненность - доминантность», фактор $M$ «практичность - развитое воображение», фрактор Н - «смелость - робость», Q4 «расслабленность напряженность». Между фрактором E «подчиненность - доминантность» и наличием критического мышления обнаружена положительная корреляция. Люди, мыслящие критически, отличаются потребностью чувствовать власть в своих руках, они независимы, самоуверенны, упрямы, иногда даже до агрессивности. Представители этой категории независимы в суждениях и поведении, иногда свой образ мыслей склонны считать единственно правильным. В общении чаще всего сами являются инициаторами дискуссий и споров. Для них характерны независимость в мышлении, упрямство (доминантность), самоуверенность, стремление руководствоваться собственными правилами поведения и командовать другими, настойчивость, напористость, враждебность и авторитарность. Люди, не способные критически мыслить, наоборот склонны уступать дорогу другим, часто оказываются зависимыми, тревожатся о возможных ошибках. Им свойственны покорность, застенчивость, желание принимать чужую точку зрения.

Следующим фактором, имеющим положительную связь с критическим мышлением, является фактор $M$ - «практичность - развитое воображение». Старшеклассники с критическим мышлением обладают высоким творческим потенциалом, развитым воображением. Они ориентированы на свой внутренний мир и ко всему ищут оригинальный творческий подход. У людей практичных, ориентирующихся на общепринятые нормы, будет наблюдаться низкая способность к критическому мышлению.

Обнаружена положительная связь между критическим мышлением и фактором H - «смелость - робость». Старшеклассники с критическим мышлением имеют выраженными смелость, предприимчивость, активность в социальных контактах; наличие эмоциональных интересов, готовность к риску и сотрудничеству с незнакомыми людьми в незнакомых обстоятельствах, способность принимать самостоятельные, неординарные решения, склонность к авантюризму и проявлению лидерских качеств. 
Также была обнаружена отрицательная связь между критическим мышлением и фактором Q4 - «расслабленность - напряженность». На основании этого можно говорить о том, что старшеклассники с выраженным критическим стилем мышления менее напряжены и скованы. Старшеклассники, у которых отсутствует критичность мышления, более подвержены фррутрации. Таким образом, старшеклассники, умеющие грамотно высказывать свою позицию, аргументировать свои положения, вести спор, чувствуют себя спокойно и уверенно.

У старшеклассников с критическим мышлением обнаружена значимая положительная связь между мотивацией успеха и критическим стилем мышления. Другими словами, анализ полученных результатов показывает, что чем сильнее развито критическое мышление, тем выше мотивация успеха.

Таким образом, проведённое исследование позволяет говорить о наличии определённых личностных качеств, которые характерны старшеклассникам с выраженным критическим мышлением. К ним относятся: доминантность, развитое воображение, смелость и авантюрность, спокойность и отсутствие скованности, выраженная мотивация на успех. Это творческие личности, способные занимать лидирующие позиции.

\section{Литература}

1. Белоусова А.К., Пищик В.И. Стиль мышления. Учебное пособие. Ростов-наДону: ЮФУ, 2011.

2. Брюшинкин В.Н. Критическое мышление и аргументация //Критическое мышление, логика, аргументация/Под ред. В.Н. Брюшинкина, В.И. Маркина. Калининград: Изд-во КГУ, 2003. С.29-34.

3. Волков Е.В. Развитие критического мышления. М., 2004.

4. Галицких Е.О. Диалог в образовании как способ становления толерантности. М.: Академический проект, 2004. 240 с.

5. Молохина Г.А. Возрастные и гендерные особенности стиля мышления студентов. Автореф. дисс. ... к. психол. н.. Ростов-на-Дону, 2010.

6. Сорина Г.В. Критическое мышление: история и современный статус //Вестник Московского университета. Серия 7. Философия. № 6. 2003. С. 97-110.

7. Федотовская Е.И. Методика развития критического мышления как важного фактора формирования иноязычной коммуникативной компетенции в специализированных вузах. Автореф. дис. ... канд. пед. наук. М., 2005.

8. Халперн Д. Психология критического мышления. СПб.: Питер, 2000.

9. Шаповаленко И.В. Возрастная психология. М.: Академия, 2004.

10. Пол, Р. Критическое мышление: Что необходимо каждому для выживания в быстро меняющемся мире

11. http://www.evolkov.net/critic.think/Paul.R/Paul.R.Critical.thinking.04.html 


\section{PERSONAL QUALITIES OF SECONDARY SCHOOL STUDENTS WITH CRITICAL THINKING}

Belousova A.K. (Don State Technical University, Rostov-on-Don, Russia)

The article provides an overview of modern ideas about critical thinking. Based on the analysis of research, the author reveals the features of critical thinking characteristic of high school students, identifies the psychological determinants of the development of critical thinking. The author formulates his own position, which is based on the idea of the dominance of the selection function in the processes of thinking of people with dominant critical thinking. The function of selection, according to the author, is to assess, select, screen out and verify information received by a person. The author formulates the hypothesis of the study, according to which high school students have a certain set of psychological factors and features of the motivation to achieve success, which are associated with critical thinking. The results of an empirical study of critical thinking of high school students, which demonstrate the relationship of factors $E, M, H$, Q4 with critical thinking, are presented.

Keywords: critical thinking, psychological determinants, reflexivity, adolescence, appraisal activity, independent thinking. 